\title{
Espectro de Gotas de Pontas de Pulverização com Adjuvantes DE Uso Agrícola ${ }^{1}$
}

\author{
Droplet Spectra of Spray Nozzles with Agricultural Adjuvants \\ CUNHA, J.P.A.R. ${ }^{2}$, BUENO, M.R. ${ }^{3}$ e FERREIRA, M.C. ${ }^{4}$
}

\begin{abstract}
RESUMO - O sucesso de uma boa aplicação de produtos fitossanitários depende da sinergia entre fatores como tamanho de gota, tipo de ponta, pressão, volume e composição da calda e características do alvo. Assim, o objetivo deste trabalho foi avaliar o espectro de gotas produzidas por pontas de jato plano defletor (TT 11002) e jato plano defletor com indução de ar (TTI 11002), com diferentes adjuvantes adicionados à calda de pulverização, pela técnica de difração de raio laser. O experimento foi conduzido em delineamento inteiramente casualizado, com quatro repetições, em esquema fatorial $2 \times 5$, ou seja, duas pontas de aplicação (jato plano defletor e jato plano defletor com indução de ar) e cinco composições de calda (água e água mais quatro adjuvantes: fosfatidilcoline+ácido propiônico, éter poliglicólico de monilfenol, ésteres de ácidos graxos e nonil-fenol etoxilado+óxido de etileno). Em ambiente controlado, avaliou-se o espectro de gotas, por meio de um analisador a laser de gotas em tempo real, na pressão de $276 \mathrm{kPa}$. O efeito dos adjuvantes no espectro de gotas mostrou-se dependente da ponta de pulverização empregada. A adição dos adjuvantes à calda não alterou o risco potencial de deriva, expresso pela porcentagem do volume em gotas com diâmetro inferior a $100 \mu \mathrm{m}$, porém o adjuvante fosfatidilcoline+ácido propiônico reduziu o diâmetro da mediana volumétrica das gotas produzidas pela ponta de jato plano defletor com indução de ar, em relação à avaliação feita somente com água.
\end{abstract}

Palavras-chave: calda de pulverização, surfatantes, tecnologia de aplicação, tamanho de gotas.

\begin{abstract}
The success of an efficient pesticide application depends on the synergy among factors such as droplet size, nozzle type, pressure, spray volume, spray tank mixture and target. The aim of this work was to evaluate the spectrum of droplets produced by turbo flat-fan (TT 11002) and air induction turbo flat-fan (TTI 1 1002) spray nozzles, with different adjuvants added to the tank mix, using the laser diffraction technique. The experiment was carried out in a completely randomized design, with four replications in a factorial model $2 x 5$, i.e., two spray nozzles (turbo flat-fan and airinduction turbo flat-fan) and five spray mixtures (water and water plus four adjuvants (phosphatidylcholine+propionic acid, nonylphenol polyglycolic ether; fatty acid esters and ethoxylated nonylphenol+ethylene oxide). In a controlled atmosphere, the droplet spectrum was evaluated through a real time laser particle size analyzer, at a pressure of $276 \mathrm{kPa}$. The effect of the adjuvant on the droplet size was shown to be dependent on the spray nozzle. Addition of an adjuvant did not alter drift risk, expressed by the percentage of spray volume in droplets smaller than $100 \mu \mathrm{m}$; however, the adjuvant phosphatidylcholine+propionic acid reduced the volumetric median diameter of the droplets produced by the air induction turbo flat-fan nozzle, compared to the evaluation with water alone.
\end{abstract}

Keywords: spray mixture, surfactants, application technology, droplet size.

1 Recebido para publicação em 27.4.2010 e na forma revisada em 17.12.2010.

2 Professor, Dr., Instituto de Ciências Agrárias, Universidade Federal de Uberlândia - ICIAG/UFU, 38400-902 Uberlândia-MG, <jpcunha@iciag.ufu.br>; ${ }^{3}$ Aluna do Programa de Pós-Graduação em Agronomia, ICIAG/UFU; ${ }^{4}$ Professor, Dr., Faculdade de Ciências Agrárias e Veterinárias, Universidade Estadual Paulista - UNESP, 14884-900 Jaboticabal-SP. 


\section{INTRODUÇÃO}

A eficiência da tecnologia de aplicação é determinada, dentre outros fatores, pela adequada colocação e distribuição do produto fitossanitário no alvo. Para isso, a escolha da ponta de pulverização é fundamental para que se obtenha uma gota de tamanho ideal, porém essa escolha deve estar diretamente associada a fatores como tamanho de gotas desejado, velocidade de distribuição do líquido, volume de calda, condições ambientais (Miller \& Butler Ellis, 2000), pressão de trabalho, formulação dos produtos químicos e características da calda e do alvo.

Durante as aplicações, o ideal é que o espectro de gotas seja homogêneo, isto é, que se produzam gotas de mesmo tamanho. Deve-se cuidar para que não sejam produzidas gotas muito grossas nem muito finas, evitando-se assim perdas por deriva e escorrimento. É preciso conhecer as características técnicas das pontas, visando à sua correta seleção e, com isso, aplicações eficientes e seguras ambientalmente. Nas pontas de pulverização que operam com pressão hidráulica, a formação de gotas, muitas vezes, é bastante desuniforme, dificultando a boa cobertura do alvo (Cunha et al., 2007).

Esse processo de formação das gotas pode ser significativamente alterado pelo uso de certas formulações e pela adição de adjuvantes, visto que estes alteram características físicoquímicas das caldas, como tensão superficial e viscosidade. Além disso, a adição de componentes químicos às caldas de pulverização também pode causar interações entre os produtos aplicados e afetar negativamente o resultado de uma aplicação (Antuniassi, 2006).

Os adjuvantes são adicionados à calda de pulverização para aumentar a eficiência biológica dos ingredientes ativos. Eles atuam de maneira diferente entre si e podem promover melhorias no espalhamento, no molhamento, na aderência das gotas ao alvo, na redução de espuma e na penetração (Costa et al., 2005). Também são responsáveis pela manutenção das características físico-químicas das formulações desde a fabricação até a utilização final em campo.

A conversão de um líquido em gotas e o destino final dessas gotas dependem das propriedades físico-químicas das soluções empregadas (Prokop \& Kejklícek, 2002). O grau de quebra das gotas está diretamente ligado à viscosidade e ao escoamento da solução. Além disso, características como estabilidade e densidade também influenciam no processo de formação da gota, cujo conhecimento é fundamental para o sucesso de uma aplicação de produto fitossanitário. Cunha et al. (2003), avaliando estratégias para redução da deriva de produtos fitossanitários, concluíram que a adição de um óleo vegetal à calda altera o espectro de gotas pulverizadas, aumentando o diâmetro das gotas e diminuindo a porcentagem de gotas propensas à ação dos ventos, constituindo-se, portanto, em fator auxiliar para redução da deriva.

Em geral, adjuvantes com a função espalhante têm em sua composição ingredientes redutores de tensão superficial. Essa redução pode levar à diminuição do tamanho das gotas, porém a magnitude desse processo não é muito grande e varia de acordo com a ponta empregada (Butler-Ellis et al., 2001), com as características do agente tensoativo, bem como com a concentração utilizada na calda. Ainda segundo esses autores, os surfatantes também causam outras alterações nas propriedades de superficie das moléculas, além da tensão superficial, que podem influenciar a formação das gotas.

O uso de adjuvantes é prática recomendável em muitas situações, pelo fato de eles promoverem alterações na calda de pulverização, possibilitando, por exemplo, minimizar os efeitos do ambiente que podem comprometer a eficiência de um tratamento fitossanitário (Carbonari et al., 2005). Contudo, grande parte dos problemas advindos do uso desses aditivos na calda origina-se do desconhecimento de sua ação e das implicações de seu emprego na eficiência de controle do alvo preconizado na aplicação (Antuniassi, 2006), inclusive em relação ao espectro de gotas gerado. Pouca informação científica existe sobre o assunto, dificultando a seleção ou a recomendação deles.

Em razão disso, o objetivo deste trabalho foi avaliar o efeito de diferentes adjuvantes adicionados à calda de pulverização no espectro de gotas geradas por pontas de jato plano defletor e jato plano defletor com indução de ar. 


\section{MATERIAL E MÉTODOS}

A análise do espectro de gotas foi realizada utilizando-se um analisador de partículas Mastersizer $\mathbf{S}^{\circledR}$, da Malvern Instruments Ltd. Este baseia-se na medição da luz (feixe de raio laser) difratada durante a passagem das gotas pulverizadas pela região de amostragem do aparelho (Schick, 1997).

$\mathrm{O}$ experimento foi conduzido em delineamento inteiramente casualizado, com quatro repetições (foram escolhidos aleatoriamente e utilizados quatro exemplares de pontas de cada modelo, cada qual correspondente a uma repetição), em esquema fatorial $2 \times 5$, sendo duas pontas de pulverização (jato plano defletor com indução de ar - TTI 11002 e jato plano defletor - TT 11002) e cinco composições de calda (água e água mais quatro diferentes adjuvantes, conforme descrito na Tabela 1).

O bico de pulverização foi instalado a $0,4 \mathrm{~m}$ de distância do feixe de laser e movimentado $55^{\circ}$ para a direita e para a esquerda, com o intuito de que todo o jato atravessasse o feixe. Para manter a pressão de líquido constante $(276 \mathrm{kPa})$, utilizou-se de ar comprimido controlado com regulador de pressão de precisão, operado manualmente, munido de manômetro analógico calibrado. $\mathrm{O}$ acionamento do fluxo de calda e do mecanismo de movimentação do bico foi realizado simultaneamente, por meio de interruptor elétrico que comanda a válvula solenoide do circuito hidráulico e o mecanismo de oscilação do bico.

As condições ambientais durante a realização dos experimentos foram: temperatura do ar inferior a $28{ }^{\circ} \mathrm{C}$, umidade relativa do ar superior a $60 \%$ e ausência de ventos e de luminosidade externa, uma vez que as análises foram realizadas com as luzes apagadas.

A decodificação dos dados foi realizada pelo software Mastersizer S versão 2.19 (Malvern Instruments Co.). Os valores relacionados ao espectro de tamanho de partículas foram processados e tabulados diretamente pelo software, sendo apresentados de forma tabelada.

Foram processadas duas leituras para cada ponta e realizada a média dos resultados das análises, utilizadas para avaliar os seguintes parâmetros: $\mathrm{Dv}_{0,1}$ - diâmetro de gota tal que $10 \%$ do volume do liquido pulverizado é constituído de gotas de tamanho menor que esse valor; $\mathrm{Dv}_{0.5}$ - diâmetro de gota tal que $50 \%$ do volume do líquido pulverizado é constituído de gotas de tamanho menor que esse valor, também conhecido como diâmetro da mediana volumétrica (DMV); $\mathrm{Dv}_{0,9}$ - diâmetro de gota tal que $90 \%$ do volume do líquido pulverizado é constituído de gotas de tamanho menor que esse valor; e AR - amplitude relativa e porcentagem do volume em gotas com diâmetro inferior a $100 \mu \mathrm{m}$.

A amplitude relativa (AR) foi determinada utilizando-se a seguinte equação:

$$
A R=\frac{D v_{0,9}-D v_{0,1}}{D v_{0,5}}
$$

Os dados de espectro do tamanho de gotas foram submetidos à análise de variância $\mathrm{e}$, constatada diferença significativa, as médias foram comparadas pelo teste de Tukey $(p<0,05)$. Foram aplicados os testes de Lilliefors e Bartlett para verificar a normalidade dos erros e a homogeneidade das variâncias.

Tabela 1 - Adjuvantes e dosagens avaliadas no estudo de espectro de gotas

\begin{tabular}{|l|c|c|c|}
\hline \multicolumn{1}{|c|}{ Composição básica do adjuvante } & Nome comercial & Indicação de uso & $\begin{array}{c}\text { Dosagem } \\
(\% \mathrm{v} \mathrm{v})\end{array}$ \\
\hline Fosfatidilcoline+ácido propiônico $\left(712,88 \mathrm{~g} \mathrm{~L}^{-1}\right)$ & LI 700 & $\begin{array}{c}\text { Espalhante adesivo e } \\
\text { acidificante }\end{array}$ & 0,50 \\
\hline Éter poliglicólico de monilfenol $\left(150 \mathrm{~g} \mathrm{~L}^{-1}\right)$ & Espalhante Adesivo Du Fol & Espalhante adesivo & 0,10 \\
\hline Óleo vegetal - ésteres de ácidos graxos $\left(860 \mathrm{~g} \mathrm{~L}^{-1}\right)$ & Óleo vegetal Du Fol & Espalhante adesivo & 0,50 \\
\hline Nonil-fenol etoxilado+óxido de etileno $\left(120 \mathrm{~g} \mathrm{~L}^{-1}\right)$ & Antideriva & $\begin{array}{c}\text { Espalhante adesivo e } \\
\text { antideriva }\end{array}$ & 0,15 \\
\hline
\end{tabular}




\section{RESULTADOS E DISCUSSÃO}

Encontram-se, na Tabela 2, os diâmetros médios dos volumes acumulados de 10 e $50 \%$. Percebe-se, para as duas variáveis, que a interação entre pontas e tipos de calda foi significativa, indicando a dependência entre os dois fatores. Em todas as condições, a ponta de jato plano defletor com indução de ar (TTI 11002) gerou gotas de maior tamanho, com DMV médio de $635 \mu \mathrm{m}$, como era esperado; contudo, os efeitos das diferentes composições de calda no espectro de gotas não foram semelhantes entre elas. Possivelmente, essa diferenciação ocorreu devido à complexidade do processo de formação de gotas em pontas de indução de ar, ainda pouco conhecido e estudado.

O sistema Venturi presente nessas pontas, combinado ao pré-orifício, permite formação de gotas de maior tamanho com pequenas bolhas de ar em seu interior (Nuyttens et al., 2007). Viana et al. (2007), avaliando o tamanho de gotas das pontas de jato plano de indução de ar LA-1JC e SR-1, encontraram DMV variando de 658 a $1.363 \mu \mathrm{m}$. De acordo com esses autores, gotas desse tamanho são indicadas para evitar perdas por deriva e volatilização, sendo ideais para aplicação de herbicidas em préemergência e herbicidas sistêmicos em pós-emergência. Entretanto, dependendo de fatores inerentes à constituição química e fisica da folha de algumas plantas daninhas, há potencial risco de escorrimento das gotas, interferindo no controle destas.

Miller \& Butler-Ellis (2000), estudando o efeito das formulações nas características da pulverização, argumentam que as pontas com indução de ar são mais sensiveis às mudanças nas propriedades físicas da calda e que seu comportamento nem sempre segue o das pontas hidráulicas convencionais. Isso possivelmente ocorre em função da interação líquido-ar dentro da ponta.

Analisando o DMV, verifica-se que a adição dos adjuvantes à água não o alterou estatisticamente nas pontas de jato plano defletor. Entretanto, o adjuvante fosfatidilcoline+ácido propiônico levou a uma redução de $36 \%$ em seu valor com a ponta de indução de ar. Isso mostra que o efeito da adição de um adjuvante não pode ser generalizado, pois existe interação com a ponta de pulverização. Downer et al. (1998) também mostraram que o efeito da adição de adjuvantes na pulverização é um processo complexo, que dificulta o estabelecimento de relações claras e diretas.

Cunha \& Alves (2009), estudando as propriedades físico-químicas de caldas de pulverização com alguns adjuvantes, comentam que, em geral, a elevação da viscosidade da calda com adjuvantes está associada à geração de gotas de pulverização maiores e, portanto, com efeito no potencial de deriva de uma aplicação. No entanto, não está definida a magnitude da

Tabela 2 - Distribuição volumétrica por classe de tamanho ( $\mathrm{Dv}_{0,1}$ e $\left.\mathrm{DMV}\right)$ das gotas pulverizadas por pontas de jato plano defletor e jato plano defletor com indução de ar, com caldas de diferentes adjuvantes

\begin{tabular}{|c|c|c|c|c|c|c|}
\hline \multirow{3}{*}{ Calda } & \multicolumn{3}{|c|}{$\mathrm{Dv}_{0,1}(\mu \mathrm{m})$} & \multicolumn{3}{|c|}{$\operatorname{DMV}(\mu \mathrm{m})$} \\
\hline & \multicolumn{2}{|c|}{ Ponta de pulverização } & \multirow{2}{*}{ Média } & \multicolumn{2}{|c|}{ Ponta de pulverização } & \multirow{2}{*}{ Média } \\
\hline & TTI 11002 & TT 11002 & & TTI 11002 & TT 11002 & \\
\hline Água & $257 \mathrm{Aa}$ & $85 \mathrm{Ba}$ & 171 & 708Aa & $201 \mathrm{Ba}$ & 455 \\
\hline Água + fosfatidilcoline & $193 \mathrm{Ab}$ & $77 \mathrm{Ba}$ & 135 & $452 \mathrm{Ab}$ & $178 \mathrm{Ba}$ & 315 \\
\hline Água + éter poliglicólico de monilfenol & $248 \mathrm{Aa}$ & $75 \mathrm{Ba}$ & 162 & $665 \mathrm{Aa}$ & $184 \mathrm{Ba}$ & 425 \\
\hline Água + ésteres de ácidos graxos & $228 \mathrm{Aab}$ & $76 \mathrm{Ba}$ & 76 & 659Aa & $184 \mathrm{Ba}$ & 422 \\
\hline Água + nonil-fenol etoxilado & $258 \mathrm{Aa}$ & $77 \mathrm{Ba}$ & 168 & $691 \mathrm{Aa}$ & $187 \mathrm{Ba}$ & 439 \\
\hline Média & 239 & 78 & & 635 & 187 & \\
\hline Valor de F (Calda x Ponta) & & $4,02 * *$ & & & $9,99 * *$ & \\
\hline $\mathrm{CV}(\%)$ & & 11,81 & & & 10,72 & \\
\hline
\end{tabular}

$\mathrm{Dv}_{0,1}$ - diâmetro de gota tal que $10 \%$ do volume do líquido pulverizado é constituído de gotas menores que esse valor; DMV- diâmetro de gota tal que $50 \%$ do volume do líquido pulverizado é constituído de gotas menores que esse valor $\left(\mathrm{Dv}_{0,5}\right)$. Médias seguidas por letras distintas maiúsculas, nas linhas, e minúsculas, nas colunas, diferem entre si a 0,05 de probabilidade pelo teste de Tukey. ${ }^{* *}$ significativo a 0,01 . 
elevação necessária para o aumento do diâmetro das gotas.

Na Tabela 3, tem-se o diâmetro médio do volume acumulado de $90 \%$ e a amplitude relativa do espectro das gotas. A interação entre pontas e tipos de calda não foi significativa, indicando a independência entre os fatores.

É possivel verificar que a amplitude relativa do tamanho das gotas não foi influenciada pelos fatores avaliados. Os valores obtidos variaram de 1,47 a 1,84 . À medida que se deseja aumentar a qualidade da pulverização, deve-se exigir mais do desempenho das pontas e, especialmente, da homogeneidade do espectro de gotas. Numericamente, quanto maior o valor da amplitude relativa, mais desuniformes serão as gotas. Espectro de gotas homogêneo tem valor de amplitude relativa tendendo a zero.

O DMV e a amplitude relativa devem ser analisados conjuntamente para a caracterização da pulverização. Isoladamente, o DMV fornece um valor de referência, sem indicar a dispersão dos dados em torno desse valor. A amplitude relativa indica a homogeneidade do espectro de tamanho das gotas. Assim, além de avaliar os efeitos dos adjuvantes no tamanho das gotas, é importante avaliar também seu efeito na uniformidade destas.

Em relação ao $\mathrm{Dv}_{0,9}$, novamente os menores valores foram verificados para a calda com o adjuvante fosfatidilcoline, cujos valores foram estatisticamente menores que a calda com o adjuvante nonil-fenol etoxilado (Tabela 3 ).

Na Tabela 4 é mostrada a porcentagem do volume aspergido com gotas de diâmetro menor que $100 \mu \mathrm{m}$. Quanto menor essa porcentagem, menor o risco de deriva durante a aplicação. Não existe valor-padrão indicativo de risco de deriva ou de aplicação segura. Em geral, valores inferiores a $15 \%$ do volume pulverizado composto por gotas com diâmetro inferior a $100 \mu \mathrm{m}$ parecem ser mais adequados a uma aplicação segura (Cunha et al., 2003).

A ponta de jato plano defletor (TT 11002) gerou um espectro de gotas mais sujeito à deriva, portanto seu uso deve ser feito com critério, evitando-se aplicações com velocidade do vento elevada. Com relação à adição dos adjuvantes, não houve efeito significativo. Apesar de o adjuvante fosfatidilcoline+ácido propiônico ter reduzido o DMV com a ponta de indução de ar, essa diminuição não causou aumento na porcentagem do volume composto por gotas menores que $100 \mu \mathrm{m}$ suficiente para influenciar estatisticamente o risco potencial de deriva.

Esses resultados estão de acordo com os apresentados por Iost (2008). Ela avaliou o efeito de adjuvantes com potencial antideriva (nonil-fenol etoxilado+óxido de etileno, fosfatidilcoline+ácido propiônico, nonil-fenol etoxilado, lecitina e polímero glicol silano) no tamanho de gotas e verificou pouco efeito destes no DMV e na porcentagem de volume

Tabela 3 - Distribuição volumétrica por classe de tamanho $\left(\mathrm{Dv}_{0,9}\right)$ e amplitude relativa das gotas pulverizadas por pontas de jato plano defletor e jato plano defletor com indução de ar, com caldas de diferentes adjuvantes

\begin{tabular}{|c|c|c|c|c|c|c|}
\hline \multirow{3}{*}{ Calda } & \multicolumn{3}{|c|}{$\mathrm{Dv}_{0,9}(\mu \mathrm{m})$} & \multicolumn{3}{|c|}{ AR } \\
\hline & \multicolumn{2}{|c|}{ Ponta de pulverização } & \multirow{2}{*}{ Média } & \multicolumn{2}{|c|}{ Ponta de pulverização } & \multirow{2}{*}{ Média } \\
\hline & TTI 11002 & TT 11002 & & TTI 11002 & TT 11002 & \\
\hline Água & 1.294 & 436 & $865 \mathrm{ab}$ & 1,47 & 1,74 & $1,61 \mathrm{a}$ \\
\hline Água + fosfatidilcoline & 868 & 339 & $604 \mathrm{~b}$ & 1,49 & 1,48 & $1,49 \mathrm{a}$ \\
\hline Água + éter poliglicólico de monilfenol & 1.355 & 374 & $865 \mathrm{ab}$ & 1,68 & 1,63 & $1,66 \mathrm{a}$ \\
\hline Água + ésteres de ácidos graxos & 1.433 & 389 & $911 \mathrm{ab}$ & 1,79 & 1,71 & $1,75 \mathrm{a}$ \\
\hline Água + nonil-fenol etoxilado & 1.543 & 399 & $971 \mathrm{a}$ & 1,84 & 1,72 & $1,78 \mathrm{a}$ \\
\hline Média & $1.299 \mathrm{~A}$ & $387 \mathrm{~B}$ & & $1,65 \mathrm{~A}$ & $1,66 \mathrm{~A}$ & \\
\hline Valor de F (Calda x Ponta) & \multicolumn{3}{|c|}{$2,48^{\text {ns }}$} & \multicolumn{3}{|c|}{$0,974^{\mathrm{ns}}$} \\
\hline $\mathrm{CV}(\%)$ & \multicolumn{3}{|c|}{15,34} & \multicolumn{3}{|c|}{13,59} \\
\hline
\end{tabular}

Dv0,9 - diâmetro de gota tal que $90 \%$ do volume do líquido pulverizado é constituído de gotas menores que esse valor; AR - amplitude relativa. Médias seguidas por letras distintas maiúsculas, nas linhas, e minúsculas, nas colunas, diferem entre si a 0,05 de probabilidade pelo teste de Tukey. ${ }^{\text {ns }}$ não significativo. 
Tabela 4 - Porcentagem do volume pulverizado composto por gotas com diâmetro inferior a $100 \mu \mathrm{m}$ de pontas de jato plano defletor e jato plano defletor com indução de ar, com caldas de diferentes adjuvantes

\begin{tabular}{|c|c|c|c|}
\hline \multirow{3}{*}{ Calda } & \multicolumn{3}{|c|}{ Gotas $<100 \mu \mathrm{m}(\%)$} \\
\hline & \multicolumn{2}{|c|}{ Ponta de pulverização } & \multirow{2}{*}{ Média } \\
\hline & TTI 11002 & TT 11002 & \\
\hline Água & 1,51 & 14,61 & $8,06 \mathrm{a}$ \\
\hline Água + fosfatidilcoline & 1,05 & 18,28 & $9,67 \mathrm{a}$ \\
\hline $\begin{array}{l}\text { Água + éter poliglicólico de } \\
\text { monilfenol }\end{array}$ & 1,02 & 19,09 & $10,06 \mathrm{a}$ \\
\hline Água + ésteres de ácidos graxos & 1,84 & 18,91 & $10,38 \mathrm{a}$ \\
\hline Água + nonil-fenol etoxilado & 1,46 & 18,26 & $9,86 a$ \\
\hline Média & $1,38 \mathrm{~B}$ & $17,83 \mathrm{~A}$ & \\
\hline Valor de F (Calda x Ponta) & & $1,53^{\text {ns }}$ & \\
\hline $\mathrm{CV}(\%)$ & & 13,08 & \\
\hline
\end{tabular}

Médias seguidas por letras distintas maiúsculas, nas linhas, e minúsculas, nas colunas, diferem entre si a 0,05 de probabilidade pelo teste de Tukey. ${ }^{\text {ns }}$ não significativo.

de gotas menores que $100 \mu \mathrm{m}$, nas dosagens recomendadas pelos fabricantes.

Destaca-se, ainda, que as pontas avaliadas apresentam espectro de gotas médio, para a ponta de jato plano defletor (TT 11002), e extremamente grosso, para a ponta de jato plano defletor com indução de ar (TTI 11002), de acordo com o fabricante. Dessa forma, para as classes de tamanho avaliadas, os adjuvantes não causaram grandes alterações no potencial de deriva, porém para pontas de espectro fino poderiam ocorrer resultados distintos.

De acordo com os resultados, conclui-se que o efeito dos adjuvantes no espectro de gotas mostrou-se dependente da ponta de pulverização e do produto empregado. A adição dos adjuvantes à calda não alterou o risco potencial de deriva, expresso pela porcentagem do volume em gotas com diâmetro inferior a $100 \mu \mathrm{m}$; contudo, o adjuvante fosfatidilcoline+ácido propiônico reduziu o DMV das gotas produzidas pela ponta de jato plano defletor com indução de ar (TTI 11002), em relação à avaliação feita somente com água. Os adjuvantes avaliados não influenciaram a uniformidade do espectro de gotas pulverizadas.

\section{AGRADECIMENTOS}

Ao CNPq, à Fapemig e à Capes, pelo suporte financeiro, que permitiu o desenvolvimento deste trabalho de pesquisa.

\section{LITERATURA CITADA}

ANTUNIASSI, U. R. Tecnologia de aplicação de defensivos. R. Plantio Direto, v. 15, p. 17-22, 2006

BUTLER-ELLIS, M. C.; TUCK, C. R.; MILLER, P. C. H. How surface tension of surfactant solutions influences the characteristics of sprays produced by hydraulic nozzles used for pesticide application. Colloids Surfaces A:

Physicochem. Eng. Aspects, v. 190, n. 3, p. 267-276, 2001

CARBONARI, C. A. et al. Efeito de surfactantes e pontas de pulverização na deposição de calda de pulverização em plantas de grama-seda. Planta Daninha, v. 23, n. 4, p. 725-729, 2005.

COSTA, N. V. et al. PH foliar e deposição de gotas de pulverização em plantas daninhas aquáticas: Brachiaria mutica, Brachiaria subquadripara e Panicum repens. Planta Daninha, v. 23, n. 2, p. 295-304, 2005.

CUNHA, J. P. A. R.; ALVES, G. S. Características físicoquímicas de soluções aquosas com adjuvantes de uso agrícola. Interciência, v. 34, n. 9, p. 655-659, 2009.

CUNHA, J. P. A. R.; TEIXEIRA, M. M.; FERNANDES, H. C. Avaliação do espectro de gotas de pontas de pulverização hidráulica utilizando a técnica da difração do raio laser. Eng. Agríc., v. 27, p. 10-15, 2007.

CUNHA, J. P. A. R. et al. Avaliação de estratégias para a redução da deriva de agrotóxicos em pulverizações hidráulicas Planta Daninha, v. 21, n. 2, p. 325-32, 2003

DOWNER, R. A.; HALL, F. R.; THOMPSON, R. S. Temperature effects on atomization by flat-fan nozzles: implications for drift management and evidence for surfactant concentration gradients. Atomization Sprays, v. 8, n. 3, p. 241-254, 1998.

IOST, C. A. R. Efeito de adjuvantes nas propriedades físico-químicas da água e na redução de deriva em pulverizações sobre diferentes espécies de plantas daninhas. 2008. 63 f. Dissertação (Mestrado em Agronomia) - Universidade Estadual Paulista, Botucatu, 2008.

MILLER, P. C. H.; BUTLER-ELLIS, M. C. Effects of formulation on spray nozzle performance for applications from ground-based boom sprayers. Crop Protec., v. 19, n. 8, p. $609-615,2000$.

NUYTTENS, D. et al. Effect of nozzle type, size and pressure on spray droplet characteristics. Biosyst. Eng., v. 97, n. 3 , p. $333-345,2007$

PROKOP, M.; KEJKLÍCEK, R. Effect of adjuvants on spray droplet size of water. Res. Agric. Eng., v. 48, n. 4, p. 144-148, 2002.

SCHICK, R. J. An engineer's practical guide drop size. Wheaton: Spraying Systems, 1997. 28 p

VIANA, R. G. et al. Características técnicas de pontas de pulverização LA-1JC e SR-1. Planta Daninha, v. 25, n. 1, p. 211-218, 2007. 